\section{Satisfação profissional e as representações sociais de autonomia do enfermeiro na perspectiva da bioética}

Reis, Rogério Donizeti

Mestrando em Bioética pela Universidade do Vale Sapucaí (UNIVÁS). Pouso Alegre, Minas Gerais- Brasil. Contato:rogerioreisfisio@yahoo.com.br

Silva, Luciana Gonçalves da

Mestre em Bioética pela Universidade do Vale Sapucaí (UNIVÁS). Pouso Alegre, Minas Gerais- Brasil.

\section{Rocha, Luiz Roberto Martins}

Doutor em Ciências pela Universidade Federal de São Paulo (Unifesp). Professor do Mestrado em Bioética da UNIVÁS. Pouso Alegre, Minas Gerais- Brasil.

\section{Silva, José Vitor da}

Pós-doutorado em Envelhecimento e qualidade de vida pela Universidade São Francisco, Itatiba-São Paulo. Professor e coordenador do Mestrado em Bioética da UNIVÁS. Pouso Alegre, Minas Gerais- Brasil.

PALAVRAS-CHAVE: Enfermeiro. Autonomia. Bioética.

$\mathrm{O}$ presente estudo teve como objetivos avaliar a satisfação profissional dos enfermeiros gerentes de unidade; conhecer os significados de autonomia, identificar os sentimentos dos enfermeiros em relação à sua autonomia no gerenciamento $\mathrm{e}$ conhecer os motivos referentes à representação social de se ter ou não autonomia profissional. Tratou-se de uma pesquisa de abordagem quantitativa e qualitativa do tipo descritivo, exploratório e transversal. A amostra do estudo foi de 60 enfermeiros (20 do qualitativo), ambos os sexos e gerentes de unidade do HCSL. A amostragem foi teórica ou intencional. A coleta de dados foi realizada por meio de um instrumento adaptado e validado culturalmente à realidade brasileira denominado Instrumento de Satisfação profissional (ISP). Para atender a parte qualitativa, foi realizado um roteiro de entrevista semiestruturado que constou de três perguntas abertas para identificar os significados, os sentimentos e os motivos de autonomia para os enfermeiros sob o referencial das representações sociais. A entrevista foi gravada e utilizou-se o método de Discurso do Sujeito Coletivo (DSC). Observou-se que $83,3 \%$ dos participantes eram do sexo feminino, com uma média de 36,1 anos de idade; $71,66 \%$ eram casados e $63,3 \%$ possuíam a média de 1,5 filhos. Quanto à faixa etária dos filhos, a que mais prevaleceu foi a de $>1$ ano e $<5$ anos com 32,7\%. Quanto à formação complementar, $66,6 \%$ possuíam pós-graduação completa, sendo a Urgência e emergência a área de atuação de maior escolha. A média de tempo de formado foi de 9,24 anos, de trabalho na assistência foi 8,9 anos e a média de tempo de trabalho no serviço atual foi de 9,2 anos. Em relação ao nível de satisfação dos enfermeiros, o componente mais importante foi autonomia, com um coeficiente de ponderação de 3,77 , e o menos importante o status profissional $(1,86)$. O alfa de Cronbach da escala global foi de 0,91 , sendo cada componente com um alfa acima 0,7 exceto status $(0,54)$. O componente que obteve maior média de pontuação foi o status profissional $(79,3)$ seguido de interação $(62,4)$ e autonomia $(60,8)$. Os significados de autonomia foram representados pelas seguintes ideias centrais: "liberdade de tomar decisão como profissional", "poder tomar decisão", "conhecimento", "realização de ações de enfermagem", "resolutividade de problemas e diversos significados". Quanto aos sentimentos, foram evidenciados pelas seguintes expressões: "Frustração", "satisfação", "impotência", "tristeza" e "sentimentos diversificados". Conclui-se que significados de autonomia se limitaram à ideologia do empoderamento profissional, enquanto os sentimentos permearam entre a dialética frustração e satisfação, predominando a frustração e gerando o sofrimento moral, que implica aspectos bioéticos no contexto profissional. A autonomia permeou entre sim, não e limitada, quando indagada sobre a sua presença no trabalho. Quanto à satisfação do enfermeiro, a autonomia foi o construto que maior obteve escore e os requisitos de trabalho o menor. Houve complementariedade entre o estudo qualitativo e quantitativo no que se refere à autonomia, permitindo a elaboração de novos itens para o componente a partir das ideias centrais que não foram condizentes com esses, contribuindo com uma proposta de complementação do Instrumento de satisfação profissional.

\section{REFERÊNCIAS}

[1] Lunardi VL, Barlem ELD, Bulhosa MS, Santos SSC, Lunardi Filho WD, Silveira RS, Bao ACP, Damolin GL. Sofrimento moral e a dimensão ética no trabalho da enfermagem. Revista Bras. Enf. Brasília, 2009, 62(4): 599603.

[2] Damolin GL, Lunardi VL, Lunardi Filho WD. O sofrimento moral dos profissionais de enfermagem no exercício da profissão. Revista de enfermagem, Rio de Janeiro; 2009, 17 (1): 35-40.

[3] Jameton A. Dilems of moral distress: moral responsability and nursing practice. Clinical Issues. 1993; 4(4): 542-51.

[4] Lunardi VL, Lunardi Filho WD, Silveira RS, Silva MRS, Dei Svaldi JS, Bulhosa MS. A Ética na enfermagem e sua relação com poder e organização do trabalho. Revista Latinoam. Enferm. 2007, maio-jun., 15(3).

[5] Schramm FR. Bioética da proteção: ferramenta válida para enfrentar problemas morais na era da globalização. Revista bioética, 2008, 16(1): 11-23. 